\title{
El marxismo en México. Una historia intelectual
}

\author{
Adrián Gerardo Rodríguez Sánchez (10 https://orcid.org/0000-0003-2169-1392 \\ Doctorado en Historiografía \\ Universidad Autónoma Metropolitana-Unidad Azcapotzalco, México. \\ adrian.geros@gmail.com
}

Carlos Illades, El marxismo en México. Una historia intelectual, México, Taurus, 2018.

Desde hace varios lustros y en publicaciones diversas, Carlos Illades se ha dado a la tarea de reescribir la historia de ese conjunto de actores, movimientos e ideas que todavía pueden englobarse dentro del término "la izquierda". Ha contribuyendo con ello no sólo a abrir el panorama del desarrollo de las corrientes progresistas en nuestro país -desde las nacionalistas revolucionarias hasta las socialistas y sus derivados-, sino también, en algunos casos como en La inteligencia rebelde (2011), en repensar y actualizar sus contribuciones teóricas y políticas que parecían superadas. En ese sentido, El marxismo en México. Una historia intelectual engrosa la trayectoria de Illades. Sin embargo, realmente es apenas un esbozo para indagaciones ulteriores, puesto que contiene limitaciones de carácter vario que describiremos a continuación.

Primero, en El marxismo en México hay una falla de origen, que se extiende a otros trabajos, básicamente a La inteligencia rebelde, que Illades refiere como el antecedente de aquel. La cuestión es que el autor va descubriendo el mediterráneo a cada paso. Es cierto que en México los intelectuales marxistas fueron eclipsados por el triunfo del neoliberalismo, en el que incluso varios se refugiaron, volviéndose unos renegados de Marx. Sin embargo, eso no se tradujo en una parálisis. La labor de estos siguió por otros caminos hasta la actualidad: en revistas, círculos de estudios, periódicos, programas académicos, partidos políticos, etcétera. Tal trabajo ha sido un proceso de ensayo y error, una evolución constante, que refleja un cambio cualitativo 
en sus estrategias e ideas. Por lo mismo, llama la atención que si bien Illades revisa en su libro a autores ineludibles dentro del marxismo en México, como Vicente Lombardo Toledano, José Revueltas, Wenceslao Roces, Eli de Gortari, Pablo González Casanova, Enrique González Rojo, Bolívar Echeverría, Adolfo Gilly, Roger Bartra, Carlos Pereyra, Ruy Mauro Marini, no mencione a personajes igualmente imprescindibles y que hoy en día siguen muy activos en la academia y en la política, como Enrique Dussel, Armando Bartra, Héctor Díaz Polanco, Paco Ignacio Taibo II, Julio Moguel, Alberto Híjar Serrano, Carlos Antonio Aguirre Rojas, por mencionar solo algunos.

Illades (2018) señala y justifica tal omisión al aducir que su libro es un "instrumento para identificar temas, autores, problemas, obras y enfoques” (p.17). Pero claramente tal argumento no es suficiente en un trabajo que se expone ambicioso desde su título. Hubiera sido mejor que el autor planteara nítidamente las bases analíticas de su corte, para lo cual se requiere una visión de conjunto del proceso histórico estudiado. Por ejemplo, su lectura del marxismo sería más fructífera si el triunfo del neoliberalismo y el capitalismo contra el comunismo y socialismo a nivel internacional y local, no lo enfocara como una victoria total, sino más bien como una batalla ganada en una guerra que aún no concluye. En estas últimas décadas el marxismo en México se ha reorganizado y entrado en un proceso diverso de autocrítica, para expresarse por otros medios. Muestra de ello son los autores ya enlistado. Si Illades reconociera esas nuevas rutas podría haber generado conclusiones más completas en su trabajo.

Por otra parte, El marxismo en México carece de un método bien delimitado. Con excepción del capítulo I donde se describen dos tipos de intelectual marxista ("el intelectual orgánico" y el "intelectual comprometido") y que le sirve al autor para medianamente caracterizar a los personajes analizados, no existe la problematización amplia de algún tema central. En un principio, sin dar más referencias, Illades (2018) señala que va a "compaginar el método generacional (si vale la expresión) [sic] con los acontecimientos definitivos de una época -o un 
bloque histórico para emplear la categoría gramsciana-” (pp. 27-28). Este abordaje, que nunca es retomado explícitamente a lo largo del texto, se combina con una cronología lineal, no problematizada tampoco, pero que abarca aproximadamente de 1919 a 1991 . Sin duda estamos ante una biografía colectiva de marxistas en México, en el que, no obstante, no es posible vislumbrar cuál es el método generacional que usa el autor, aun cuando en México existen historiadores como Luis González y González o Wigberto Jiménez Moreno, que lo teorizaron o practicaron también, por no hablar del método prosopográfico, bien conocido entre historiadores.

Otro problema se encuentra en la ambigüedad del concepto "historia intelectual" que subtitula el libro. A diferencia de otros trabajos, donde el autor da una definición (Illades y Suárez, 2012, p. 11), en El marxismo en México no aparece. Esto conlleva cerrar el diálogo, por un lado, con las innovaciones de la llamada "nueva historia intelectual”, en la que confluyen las herramientas de la teoría de la recepción, la historia del libro y la lectura, el giro lingüístico, la historia conceptual, entre otras, y que han discutido abundantemente y analizado para América Latina autores como Palti (2007) y Polgovsky (2010). Por otro lado, esta ambigüedad dificulta el intercambio de problemáticas con aquella tradición de estudios que ha abordado la recepción de Marx en América Latina, como los de José María Aricó (2005) y Horacio Tarcus (2013), por mencionar los más representativos. Los trabajos del primero son clásicos dentro de la misma tradición marxista. El segundo integra la perspectiva marxista con los enfoques de la nueva historia intelectual, dando como resultado un producto ahora imprescindible para cualquier estudioso del tema. Por lo mismo, metodológicamente Illades dialoga poco con la obra de estos autores. Sin embargo, hay ciertos puentes entre ellos que es posible localizar a contrapelo.

Los estudios de la recepción del marxismo en América Latina han enfatizado la necesidad de descentralizar el análisis tradicional de la historia de las ideas. Por ejemplo, animan a revisar las vías de expansión del marxismo, con el trabajo de las editoriales y la labor de revistas, 
pero también con el estudio de las formas en que los lectores se apropiaron de estos textos, reconociendo la heterodoxia de cada lectura particular. Con este proceder se logra rescatar la contribución de personajes olvidados o poco atendidos: traductores, impresores, profesores de nivel medio, líderes sindicales, archivistas. Con base a esto, se puede observar que el libro de Illades se mantiene en una historia intelectual tradicional (como hace en La inteligencia rebelde), porque se centra en figuras de primer nivel de un marxismo académico o intelectual, pero no va más allá del estudio de la fase de producción (escritura, impresión, ideas), faltando conocer su distribución y recepción.

Por estas razones se afirma la limitada problematización histórica en El marxismo en México. En él se echa de menos un planteamiento sobre la relación del marxismo académico con las iniciativas de preservación de la cultura marxista o sus vínculos con movimientos armados u otras tendencias ideológicas, como la Teología de la Liberación; problemas historiográficos que se personifican, por ejemplo, en la figura de Arnoldo Martínez Verdugo como creador del Centro de Estudios del Movimiento Obrero y Socialista o en las acciones de la Liga Comunista 23 de Septiembre.

De cualquier forma, debido sobre todo a la variada documentación consultada (artículos y libros especializados, entrevistas, periódicos y extrañamente solo tres archivos) Illades abre una brecha de investigación que anima a descentralizar el análisis. Por ejemplo, hay temas que toca que ya fueron investigados, pero que se pueden ampliar mucho más, como el trabajo de las editoriales o librerías marxistas, en el caso de la Librería Navarro o las Ediciones Frente Cultural. Otros temas los menciona igualmente de manera breve, pero han sido nulamente investigados, como la tarea educativa, editorial y de investigación de los profesores normalistas José Mancisidor, Alfonso Teja Zabre, Rafael Ramos Prudenza y Luis Chávez Orozco, así como las revistas El Maestro Rural y la Revista de Educación -aunque para la primera Palacios (1999) ya 
realizó una contribución fundamental, pero no desde el enfoque marxista. En estos casos la escritura de Illades es más la de un cronista del marxismo que la de un historiador del mismo.

Illades revela su contribución como historiador en sus análisis de las ideas o evolución ideológica de los personajes seleccionados. Es ejemplar la forma en que expone cómo Vicente Lombardo Toledano se convirtió al marxismo: del idealismo aprendido con Antonio Caso en la universidad, pasó a asumir el materialismo histórico-dialéctico de Marx, para luego renegar de su maestro y pelearse con él. Es interesante este aspecto porque muestra cómo el marxismo puede variar en su encuentro con otras tendencias intelectuales en territorios y momentos diferentes: en la controversia con Lombardo Toledano, Caso relacionaba a Marx con el positivismo, escuela de pensamiento identificada con el régimen autoritario del general Porfirio Díaz, que los ateneístas, como Caso, combatieron desde el idealismo. Variaciones de las mismas corrientes intelectuales también se encontraron y se enfrentaron en la obra de Gramsci y Mariátegui, originando productos diferentes a las ideas de Lombardo Toledano (Aricó, 1978, pp. XI-LVI).

Otros análisis son igualmente estimulantes. En particular llaman la atención las notas a la recepción de Althusser y Gramsci en México, integradas bajo el título "La renovación teórica". Las apropiaciones de Gramisci que hicieran el filósofo español desterrado, Adolfo Sánchez Vásquez (para su concepción de la teoría de la praxis) o las de Carlos Pereyra y Roger Bartra (que les permitieron salir del economicismo y repensar en sus obras las condiciones para la formación de la hegemonía política) son dignas de una revisión detenida por ser sugerentes. Se puede decir lo mismo del apartado dedicado a la tarea de traductor de El Capital de Wenceslao Roces, puesto que paralelamente a la redacción de este, se acaba de publicar un libro que también rescata la labor del español republicano como traductor de la "biblia del proletariado" (Tarcus, 2018). 
En esencia, El marxismo en México es un trabajo dispar. Por momentos es crónica, en otros es historia intelectual tradicional, en otros un conjunto de análisis eruditos. Su mérito es ser un intento de síntesis. Un abordaje claro hubiera permitido concatenar la diversidad aportaciones indudables que se desbordan a lo largo de las páginas. Por ello se afirma que se trata realmente de un esbozo, algo que contradice la pretensión de su título. A esto se suma un método de citas que vuelve difícil localizar las referencias en la bibliografía, aunque al final se inserta un índice analítico que es bastante útil. Como sea, el libro abre una puerta grande de investigación, por lo que se espera que las próximas indagaciones que inspire (que seguro lo hará) tomen nota de las problemáticas por resolver y aborden con otras herramientas intelectuales la apasionante historia del marxismo en México.

\section{Referencias}

Aricó, J. M. (1978). Mariátegui y los orígenes del marxismo latinoamericano. México: Ediciones Pasado y Presente.

Aricó, J. M. (2005). La cola del diablo. Itinerario de Gramsci en América Latina. Buenos Aires: Siglo Veintiuno Editores.

Illades, C. (2011). La inteligencia rebelde. La izquierda en debate público en México, 19681989. México: Océano.

Illades, C. (2018). El marxismo en México. Una historia intelectual. México: Taurus.

Illades, C. y Suárez, R. (2012). México como problema. Esbozo de una historia intelectual. México: UAM-Iztapalapa/UAM-Cuajimalpa/Siglo Veintiuno Editores.

Palacios, G. (1999). La pluma y el arado. Los intelectuales pedagogos y la construcción sociocultural del "problema campesino". México: El Colegio de México.

Palti, E. J. (2007). La nueva historia intelectual y sus repercusiones en América Latina. História Unisinos, 11(3), 297-305. Recuperado de

http://revistas.unisinos.br/index.php/historia/article/view/5908

Polgovsky Ezcurra, M. (2010). La historia intelectual latinoamericana en la era del "giro lingǘstico”. Nuevo Mundo Mundos Nuevos. Recuperado de https://journals.openedition.org/nuevomundo/60207 
Tarcus, H. (2013). Marx en la Argentina. Sus primeros lectores obreros, intelectuales y científicos. Buenos Aires: Siglo Veintiuno Editores.

Tarcus, H. (2018). La biblia del proletariado. Traductores y editores de El Capital en el mundo hispanohablante. Buenos Aires: Siglo Veintiuno Editores Argentina. 